\title{
THE ROLE OF DIGITALIZED VISUAL MANAGEMENT TO EMPOWER SELF- MANAGED CREWS IN CONSTRUCTION PROJECTS
}

\author{
Ana Reinbold ${ }^{1}$, Olli Seppänen², and Antti Peltokorpi ${ }^{3}$
}

\begin{abstract}
This theoretical study encompasses the role of digitalization in visual management (VM) applied in construction projects to increase the situational awareness (SA) of construction workers and crews. A literature review on VM, SA and self-managed crews shows that the level of digitalization in the construction industry is low when compared to other industries, that information silos are a common practice and that the decision-making processes depend largely on the construction manager role, causing a bottleneck of information and repeated time waste. As more digitalization enters construction sites and the amount and quality of available data increases, appropriate use of this data can bring meaningful improvement to construction site management. The study shows that using updated and real-time data for VM devices can increase information flow among construction workers and crews, increasing SA throughout the construction project. This can enable the construction crews to be more autonomous and self-managed, resulting in decentralized decision-making processes to solve task-related problems. Further steps for empirical research are suggested.
\end{abstract}

\section{KEYWORDS}

Lean construction, visual management, situational awareness, information flow, selfmanaged crews

\section{INTRODUCTION}

The production phase of a construction project is a complex process that encompasses many simultaneous sub-processes and activities. It often lacks transparency and centralizes information, resulting in decision-making bottlenecks (Dave et al. 2008; Akinci 2014). The construction industry has adapted different approaches from the manufacturing industry and army forces to tackle these problems, such as the Toyota Production System (TPS), lean management approaches, visual management (VM) and situational awareness (SA). Nevertheless, the adoption of these approaches is scattered throughout the industry, and case studies usually focus on the implementation of one

Doctoral Candidate, Department of Civil Engineering, Aalto University, Espoo Finland, +358 50431 2015, ana.reinbold@aalto.fi, orcid.org/0000-0002-7774-7984

2 Assistant Professor, Department of Civil Engineering, Aalto University, Espoo Finland, +358 50368 0412, olli.seppanen@aalto.fi, orcid.org/0000-0002-2008-5924

3 Assistant Professor, Department of Civil Engineering, Aalto University, Espoo Finland, +358 50371 6613, antti.peltokorpi@aalto.fi, orcid.org/0000-0002-7939-6612 
concept at a time (Tezel et al. 2016; Thomas et al. 2014; Gheisari et al. 2010), resulting in a deficiency of connection among concepts and how they can relate and impact construction work when implemented together.

$\mathrm{VM}$ as a part of lean thinking has been an important management approach to increase information distribution, bring more transparency to the construction site and enable pull production approaches with more simple and targeted communication devices (Koskela et al. 2018). The adoption of traditional VM brings benefits that have been measured in different case studies (Tezel et al. 2013, 2016). On the other hand, case studies also detected problems: the information available is often outdated and outside of workers' reach (Tezel et al. 2011). The result is that it is difficult for the construction crews to be self-managed or make decisions, which centralizes the decision-making process with the project manager role, even for task-related matters.

These problems are also a direct result of the fact that the construction industry presents very low levels of digitalization when compared to other industries. For example, in the German construction industry, only $6 \%$ of the players reported incorporating planning through building information modelling (BIM) during the design phase of construction projects (Berger 2016). The level is even lower during the production phase, in which digital tools have not been implemented at a significant level on construction sites and communication between the office and field is often done on paper (McKensey 2016).

It is often during the production phase when the dynamicity and complexity of construction operations stand out. In a construction setting, change is seen more as a rule than as an exception (Kim et al. 2003). Changes during the production phase of construction projects happen due to changes in design, supply chain effects, weather conditions or unexpected operation delays (Sawhney et al. 2003). Construction crews need to be responsive and make decisions at the right time to be able to adapt to the occurring changes. Thus, decentralizing the decision-making during the production phase is important to manage the changes that are part of the construction process.

To decentralize the decision-making process, it is necessary that construction crews on site be equipped with the most updated information, available in timely manner and with easy access. In other words, the crews must have information that increases their perception of the current situation to comprehend how the scenario changes when taking an action (Endsley 1995).

New technologies are enabling a larger volume of data collection and also increasing the quality of data (Dave et al. 2008) that can be available for construction crews, providing real-time information about the construction sites. It is possible now to collect data from construction sites through 3D laser scanning and photogrammetry (Pica et al. 2019), indoor positioning systems (IPS; Olivieri et al. 2017; Dror 2018; Dror et al. 2019; Zhao et al. 2019), Internet of Things (IoT) applications (Dave et al. 2015) and real-time images captured by drones and helmet cameras (Pirkl et al. 2016). This assortment of data can lead to a more autonomous construction crew and can be translated into meaningful information that will increase their awareness of the construction site and current production status.

One way to make the data available to crews during the production phase of construction projects is through the digitalization of VM devices with different functions within the framework devised by Galsworth (2005): order, standards, measures, controls and guarantees. This would bring together different concepts used in the construction 
industry that have their origins in the manufacturing industry and military operations, such as VM, SA and self-managed crews.

In order to explore the connections and align the understanding of concepts, the following sections present the literature review of the concepts related to VM, SA and self-managed crews. The literature review is followed by a synthesis of how digitalized VM can empower self-managed crews, a discussion on the relationship among these concepts and an analysis of their interdependence. The increasing technologies available on smart phones and their popularity have made it possible to include them as a tool to bring digitalization to construction sites. The use of cell phone applications as a means of communication on the construction site is rising, and the role of cell phone applications and their fit as VM tools is discussed under the topic of digitalization of construction. The paper focuses on the lack of information about material, equipment, other crews and planning available to construction workers and how the new technologies for data collection of construction projects can close this gap.

\section{LITERATURE REVIEW}

\section{Visual Management}

The sense of vision mediates $80 \%-85 \%$ of human perception, learning, cognition and activities (Ripley et al. 2010). Relying on vision during the execution of tasks was noticed by humans even before research confirmed its importance, and industry practitioners, even with individual efforts, have tried to make the workplace more visual. These efforts have been formally reported in the manufacturing industry for more than 30 years, especially coming from the Japanese car industry (Sugimori et al. 1977; Shingo 1989).

One of the definitions of VM is to provide information in a visual manner to those who are executing the task in a way that the information can be retrieved at a glance and immediately be transferred to the task execution (Greif 1991). VM aims to facilitate the execution of tasks by providing a quick and correct understanding of the task (Greif 1991; Galsworth 1997). Applying VM devices to signal, limit and guarantee (Shingo 1989) the correct execution of the right task at the right moment, and transforms the workplace and the task execution itself into an activity that is self-explanatory, self-ordered, selfregulated, and facilitates continuous improvement (Galsworth 1997).

The use of the early stages of VM can be tracked to the beginning of the twentieth century, when the Gantt chart was used for production control in 1917 (Moris 1994). The reported good results in the adoption of different VM devices in the manufacturing industry (Sugimori et al. 1977; Shingo 1989; Galsworth 1997) encouraged researchers and practitioners from the construction industry to adapt and transfer VM knowledge to construction projects (e.g., Koskela 1992; Formoso 2002; Tezel 2009; Koskela et al. 2018).

The use of VM devices like Kanban, Poka-yoke and Andon systems to solve construction problems due to a lack of flow understanding and reduced process transparency due to physical borders (walls and piles of materials) has been widely studied; several studies have reported successful results (e.g., Tezel et al. 2010; Biotto et al. 2014; Bascoul et al. 2017; Brandalise et al. 2018).

The different functions of VM in a workplace, such as transparency, job facilitation, job training, discipline, continuous improvement, management by facts, simplification and unification and creating shared ownership (Tezel, 2009) addressed during the 
production phase are the most common communication and information distribution problems of construction projects.

Nevertheless, implementation of VM is not a practice largely adopted by the construction industry, and when it is, it often reflects individual efforts from construction managers to improve the quality and distribution of information on construction sites rather than a company effort or practice (Tezel 2011). The information displayed is often outdated and physically distant from where the tasks are executed, and the implementation of VM in construction sites faces the challenge that the site is under constant change (Valente et al. 2019).

\section{Situational Awareness}

With its origin in military operations, situational awareness (SA) is defined as "the perception of the elements in the environment within a volume of time and space, the comprehension of their meaning and the projection of their status in the near future" (Endsley 1995). SA presents three hierarchical phases: perception of elements in the current situation, comprehension of the current situation and projection of future status.

In many construction projects, none of the involved managers and workers has an adequate level of information to know the current project situation, and thus does not understand what is happening and where, which makes it impossible to make any projection of the future status when taking an action (Dave et al. 2008; Akinci, 2014). Information about the production phase of construction projects such as activities status, logistic problems, lack of materials and equipment is usually not available, and when it is available is based on weekly meetings and status reports that are often subjective (Seppänen 2009).

The majority of the research in the field is related to military and emergency operations, and besides the potential use of SA in construction projects, the research and practical applications are still scarce and tend to explore only safety aspects (Oloufa et al. 2003; Gheisari et al. 2010). The scarcity of research on the topic is also reflected within the lean community. Using the search engine at the International Group for Lean Construction (IGLC) website to search through all published papers at the 27 international conferences, it is possible to find only three published papers mentioning the term situational awareness (Koskela et al. 2016; Dror et al. 2019; Reinbold et al. 2019). Among the current research development linking SA with construction projects is the introduction of the term situation picture, which indicates the level of accessible workflow data to be stored, refined and distributed, and the development of a conceptual model of construction information management to achieve situation picture (Kärkkäinen et al. 2019).

It is possible to correlate the lack of awareness about the project and task status with a very low level of process transparency, interruptions in work flow and wastes of time searching for decision-making information. Increasing SA during the production phase has the potential to allow better and more proactive decisions about control actions from both the project managers and workers.

Due to the increasing volume and quality of data being collected at construction sites through emerging technologies such as drones, sensors and cameras, it will be possible to make sense of these data and distribute them to the different roles during the production phase, providing a better awareness to the actors and also stimulating their autonomy in the decision-making process. 


\section{Self-Managed Crews}

To tackle high market competition, the manufacturing industry has applied many different practices such as lean management and visual management. One management practice is related to people management and is known as self-managed teams. The definition of self-managed teams is teams whose members manage themselves, assign jobs, plan and schedule work, make production- or service-related decisions and take action on problems (Wellins et al. 1990). This definition is also applied to the term autonomous crews.

The adoption of self-managed teams by the manufacturing industry was widely tested during the 1990s, and positive results reported in extensive research account for better productivity (Cohen et al. 1994; Wellins et al. 1990), higher job satisfaction (Cohen et al. 1994; Cordery et al., 1991) and increased commitment (Cordery et al. 1991). Providing the teams with the necessary information through different communication channels, including VM, and empowering them to take action not only showed results through improved productivity but also decentralized decision-making, resulting in more dynamic production unities (Cohen et al. 1994; Wellins et al. 1990).

Once again, the construction industry noticed the potential of management techniques from the manufacturing industry to solve the problems of centralization and information silos. By the end of the 1990s, research about leadership and team building in the construction industry was ongoing (Spatz 1999, 2000). Koskela (1992) stressed the importance of worker involvement for the successful implementation of lean principles. In this report, the term applied is self-directed teams, which implies proactive workers who are able to manage their tasks and are empowered to make decisions and introduce processes improvements.

Nevertheless, even with positive results, the research and practice on the topic is in very initial stages, and studies continue to highlight the centralized nature of the construction industry and the silos that characterize its information management (Dave et al. 2008; Tezel et al. 2016; Koskela et al. 2018). Once again, aiming to assess the research development inside the lean community, the search engine of the IGLC website was used to search through all published papers at the 27 international conferences. It was possible to find only two published papers mentioning the term self-managed (Abdelhamid et al. 2009; Desai at al. 2012) and three papers using the term autonomous crews (Buch et al. 2005, Miranda Filho et al. 2007; Desai et al. 2012); one of the papers (Desai et al. 2012) is returned in both searches.

When a problem or change happens during the execution of a task in the production of a construction project, the team involved in that task does not always have immediate access to the construction manager, nor do they have enough information to make the decisions; this leads to the improvisation of a solution that can enable the work to continue. There is no awareness of the impact of the improvisation in production, and often the impacts will be evident during the next weekly meeting. Meanwhile, the cascade effect has already impacted other tasks (Koskela 2004; Fireman et al. 2013).

\section{SYNTHESIS: DIGITALIZED VM TO EMPOWER SELF- MANAGED CREWS}

Self-managed crews are able to make decisions about the development of their tasks when they have SA about the construction project, which means that the information about materials, tools and other crews is available, and they are able to understand the impact of their decisions in the planned tasks (Cohen et al. 1994; Wellins et al. 1990). Visual 
management aims to provide information to construction workers applying visual means, making information available at a glance and maintaining relevant information provided to the crews at all times (Greif 1991; Galsworth 1997).

With new technologies available to collect data on construction sites and enabling the data to be collected in real time, the adoption of digitalized VM devices exposing this information to those involved in construction projects, such as crews and management, is necessary to increase information flow and enable decision-making based on updated information.

Following, two use cases are presented to exemplify how the concepts of selfmanaged crews and the use of digitalized VM are related. One case is from the perspective of workers and one is from the perspective of the site management, to provide a better understanding of how digitalized VM displaying data about activity status, location of people, materials and equipment that are collected and made available in real time can enable more self-managed crews and diminish the 'making-do' waste on construction sites.

Use case 1: In a construction project of a multi-storey building, during the phase of internal finishes, the crews' view of the production flow is interrupted by physical barriers such as walls, corridors and different floors. One of the crews working on tiling is planning to work on a certain floor. Without going to the floor and inspecting the work location, they cannot know if the material and tools are in place, nor if there is another crew working in the same place. With positioning sensors placed on the tools, materials and workers, geographic coordinates can be collected and then transformed into information, as floor number and floor area of equipment location, that could be displayed on a digital screen at the floor entrance. That could be used for visual order, and the tiling crew will be able to visualize if the tools and materials are in place and if the location is in use by another crew.

With information such as the aforementioned available to workers, they would be able to prepare the necessary tools and materials before starting the task, avoiding the waste of time searching for tools or the interruption of the task development due to lack of materials. In addition, they would be able to avoid negative interferences caused by too many crews working in the same location.

Use case 2: Using the same hypothetical situation described above of the multi-storey building and the tiling crew, the site management will only be aware of the activity status when the tiling crew reports it, or on a daily hub, on a weekly report or if a site supervisor goes to the location and inspects it. Using a static camera to capture the room where the tiling is happening, it is possible to transform the image data into information about the work progress. This could be available to the management in the same type of digital screen used for the workers, making the information available in real time and eliminating the movement waste of going to the location to update the activity status information.

The collection of data about construction sites is increasing with the use of technologies as positioning sensors. Capturing both static and dynamic images has the potential to return the collected data to the construction sites as VM information and improve the production work flows and the level of SA of both working crews and management.

\section{DISCUSSION}

Self-managed crews would be of great benefit during the production phase of construction projects, as this phase is characterized by its dynamism and often requires fast and 
responsive decision-making. Self-managed or autonomous crews are not a common feature during the production phase of construction projects, and one of the reasons for this is the lack of real-time information about the production and the availability of this information.

Throughout this phase, information about production progress is often collected manually to create status reports that are outdated, somewhat subjective and shared with the production teams during weekly (or even less frequent) meetings (Kärkkäinen et al. 2019; Seppänen 2009). This often results in a team waiting for a site manager's response to a daily task problem, causing cascade effects to many other tasks and teams. Approaches such as daily meetings and VM devices are applied to solve the lack of information, but the adoption is not observed consistently in construction projects.

Self-managed teams are only a possibility when the correct information is easy to access, updated and increases the overall SA of the teams involved in the production. During the production phase there are many challenges to increasing process transparency and the visualization and understanding of activity flows. With the continuous physical changes in the building itself, physical barriers such as walls and equipment can become interruptions in the collection, distribution and visualization of information.VM presents different tools to facilitate the execution of tasks applying visual information located where it is needed in production areas (Galsworth 1997). It distributes the information, increases process transparency and supports the visualization of flow in construction projects (Formoso 2002; Tezel et al. 2011).

The adoption of VM during the production phase increases the team's SA even when simple tools are applied, such as drawings with chalk on the walls to locate the electrical boxes. Nevertheless, the increasing use of new technologies, such as drones, tracking materials and workers with sensors, are allowing real-time data collection about the production process, and the availability of this data can increase processes transparency and the production flows can become more visible.

It is possible to find some development of cell phone applications targeting information sharing with production teams, but it is necessary to discuss here if they can be considered a VM device. So far, there is no literature directly linking VM in construction sites and the use of cell phone applications by workers. VM tools should be always visible in the workplace (Galsworth, 1997), and relevant information should be available at a glance (Greif, 1991). Cell phone applications do not fulfil these requirements because they require active searching for information rather than exposing the workers to relevant information at all times. It is necessary for workers to have their cell phone in their hand, unlock the screen of the device if needed and actively search for the application. Considering that more than one type of information is available, the worker will have to then search for the exact information needed. Listing the basic actions of taking the cell phone in hand, unlock the screen and searching for the application and the information, four active actions are required from the worker before reaching the information needed. Based on the active actions required by the worker to reach the information, we argue that this type of application cannot be considered a VM tool.

There is potential in digitalizing some VM tools to increase the real-time data shared and, in this way, increase the SA of those involved in production and empower teams to make decisions and become more autonomous.

The adoption of VM devices is often challenged by the display of outdated information and information that is misplaced (Tezel et al. 2011). Transforming the data collected with the support of new technologies into information that can be displayed 
through digital VM devices on construction sites will enable the information about the activity status, location of crews and equipment and production flow to be collected and shared in real time. Information availability will increase both the workers' and the management's awareness about the production phase.

\section{CONCLUSIONS}

Self-managed crews are only possible if updated information about the production activity status, logistics and location of other crews, materials and equipment is shared and they have SA about what is happening currently at the construction site and how their decisions affect other tasks and the project as a whole. VM is already applied at construction sites aiming to increase transparency and improve information sharing. However, VM applications reported so far have been manually updated without using the latest technologies related to digital SA.

The adoption of cell phone applications to share information at the construction site has an important role in information distribution; nevertheless, they cannot be considered a VM device since they require active information seeking. Digitalized VM devices could potentially include, for example, screens with information that is updated automatically located in strategic places, such as at floor entrances, displaying information about the tasks under development, crews and materials available on that floor.

New technological developments related to automated data collection are increasing the volume and quality of data collected and have the potential to facilitate information sharing, increasing the SA of those involved in the production phase. Better SA can enable a more extensive use of self-managed teams. Overall, it can be concluded that the use of digital VM devices to display the data collected from construction sites in real time can be the missing link to bring information to construction site workers, enabling them to be more autonomous in their tasks.

There is room for further research in the area of the need for digitalized VM devices and how they impact the production phase, as well as on the decision-making process of workers and the range of information required to enable crew autonomy. Future research on the usability of digital information by construction workers can support the understanding of which information should be displayed and how.

\section{ACKNOWLEDGMENTS}

This study was supported by DiCtion project funded by Business Finland and a consortium of companies.

\section{REFERENCES}

Akinci, B. 2014. "Situational Awareness in Construction and Facility Management." Frontiers of Engineering Management, DOI 10.15302/J-FEM-2014037

Bascoul, A.M. and Tommelein, I.D. 2017. "Visualizing Daily On-site Space Use" In: Proc. 25th Annual Conference of the International Group for Lean Construction. Heraklion, Greece, 9-12 Jul 2017: pp. 597-604.

Berger, R. 2016. "Digitalization in the Construction Industry." Publisher Roland Berger GMBH.

Biotto, C., Mota, B., Araújo, L., Barbosa, G. and Andrade, F. 2014. “Adapted Use of Andon in a Horizontal Residential Construction Project.” In: Kalsaas, B.T., Koskela, 
L. and Saurin, T.A., Proc. 22nd Annual Conference of the International Group for Lean Construction. Oslo, Norway, 25-27 Jun 2014: pp. 1295-1305.

Brandalise, F.M.P., Valente, C.P., Viana, D.D., and Formoso, C.T. 2018. "Understanding the effectiveness of Visual Management best practices in construction sites" In: Proc. 26th Annual Conference of the International Group for Lean Construction (IGLC), González, V.A. (ed.), Chennai, India. DOI: https://doi.org/10.24928/2018/0452

Cohen, S.G. and Ledford, G.E., Jr. 1994. "The effectiveness of self-managing teams: A quasiexperiment." Human Relations, 47: pp. 13-43.

Cordery, J.L., Mueller, W.S., and Smith, L.M. 1991. "Attitudinal and behavioral effects of autonomous group working: A longitudinal field study." Academy of Management Journal, 34: pp. 464-476.

Dave, B. and Kubler, S., Pikas, E., Holmström, J., Singh, V., Främling, K. and Koskela, L. 2015. "Intelligent Products: Shifting the Production Control Logic in Construction (With Lean and BIM)." Proc. 23rd Ann. Conf. of the Int'l Group for Lean Construction. Perth, Australia, 29-31 Jul 2015.

Dave, B., Koskela, L., Kagioglou, M. and Bertelsen, S., 2008. "A critical look at integrating people, process and information systems within the construction sector." In: Proc. 16th Ann. Conf. of the Int'l Group for Lean Construction, Manchester, UK, 16-18 Jul 2008.

Desai, A.P. and Abdelhamid, T.S. 2012. "Exploring Crew Behavior During Uncertain Jobsite Conditions." In: Tommelein, I.D. and Pasquire, C.L., Proc. 20th Annual Conference of the International Group for Lean Construction. San Diego, USA, 18$20 \mathrm{Jul} 2012$.

Dror, E., Zhao, J., Sacks, R. and Seppänen, O. 2019. "Indoor Tracking of Construction Workers Using BLE: Mobile Beacons and Fixed Gateways vs. Fixed Beacons and Mobile Gateways" In: Proc. 27th Annual Conference of the International Group for Lean Construction (IGLC). Dublin, Ireland, 3-5 Jul 2019: pp 831-842.

Dror, E. 2018. Improving information flow in construction projects using real-time monitoring and information visualization, MSc Thesis, Technion IIT, Israel

Endsley M.R. 1995. "Measurement of situation awareness in dynamic systems. Human Factors", 37(1): pp. 65-84.

Formoso, C.T., Santos, A.D and Powell, J. 2002. "An Exploratory Study on the Applicability of Process Transparency in Construction Sites", Journal of Construction Research, 3(1): pp. 35-54.

Fireman, M. C.T. and Formoso, C.T. 2013. "Integrating Production and Quality Control: Monitoring Making-Do and Unfinished Work." In: Formoso, C. T. and Tzortzopoulos, P., Proc. 21 st Annual Conference of the International Group for Lean Construction. Fortaleza, Brazil, 31-2 Aug 2013: pp. 515-525.

Galsworth, G.D. 1997. "Visual Systems: Harnessing the Power of Visual Workplace", New York, USA, AMACOM.

Galsworth, G.D. 2005. "Visual Workplace: Visual Thinking." Visual-Lean Enterprise Press, Portland, USA.

Gheisari, M., Irizarry, J. and Horn, D. 2010. "Situation awareness approach to construction safety management improvement." In: Egbu, C. (Ed,) Proc. 26th Annual ARCOM Conference, 6-8 September 2010, Leeds, UK, Association of Researchers in Construction Management, pp. 311-318.

Greif, M. 1991. "The Visual Factory: Building Participation through Shared Information", Productivity Press, Portland. 
Kärkkäinen, R., Lavikka, R., Seppänen, O., and Peltokorpi, A. 2019. "Situation Picture through Construction Information Management." In I. Lill, and E. Witt (Eds.), Proc. 10th Nordic Conference on Construction Economics and Organization (pp. 155-161). (Emerald Reach Proceedings Series; Vol. 2). https://doi.org/10.1108/S2516285320190000002028

Kim, K., and Paulson, C.B. 2003. "Agent-Based Compensatory Negotiation Methodology to Facilitate Distributed Coordination of Project Schedule Changes", Journal of Computing in Civil Engineering, 17(10).

Koskela, L. 2004. "Making-Do - the Eighth Category of Waste" In: Bertelsen, S. and Formoso, C.T., Proc. 12th Annual Conference of the International Group for Lean Construction. Helsingør, Denmark, 3-5 Aug 2004.

Koskela, L., Pikas, E., Gomes, D., Biotto, C., Talebi, S., Rahim, N. and Tzortzopoulos, P. 2016. "Towards Shared Understanding on Common Ground, Boundary Objects and Other Related Concepts" In: Proc. 24th Annual Conference of the International Group for Lean Construction. Boston, USA, 20-22 Jul 2016.

Koskela, L. 1992. "Application of the New Production Philosophy to Construction", Technical Report, Stanford University, Stanford, USA.

Koskela, L., Tezel, A., and Tzortzopoulos, P. 2018. "Why visual management?” In: Proc. 26th Annual Conference of the International. Group for Lean Construction (IGLC), González, V.A. (ed.), Chennai, India, pp. 250-260. DOI: doi.org/10.24928/2018/0527.

McKinsey \& Company 2016. "Imagining construction's digital future." https://www.mckinsey.com/industries/capital-projects-and-infrastructure/ourinsights/imagining-constructions-digital-future\# assessed 18/12/2019

Morris, P.W.G .1994. "The Management of Projects", Thomas Telford, London.

Olivieri, H., Seppänen, O. and Peltokorpi, A. 2017. "Real-Time Tracking of Production Control: Requirements and Solutions" In: Proc. 25th Annual Conference of the International Group for Lean Construction. Heraklion, Greece, 9-12 Jul 2017: pp. 671-678.

Oloufa, A.A., Ikeda, M. and Oda, H. 2003. "Situational awareness of construction equipment using GPS, wireless and web technologies", Automation in Construction, 12(6): pp. 737-748.

Pica, D., Abanda, F.H. 2019. "Emerging BIM-3D-Laser Scanning Integration in Construction Practice." Proc. 11th International Conference CITC-11. London, UK, 9-11 Sept 2019.

Pirk1, G., Hevesi, P., Amarislanov, O., and Lukowicz, P. 2016. "Emerging BIM-3D-Laser Scanning Integration in Construction Practice." Proc. 16th International Joint Conference on Pervasive and Ubiquitous Computing Adjunct. https://doi.org/10.1145/2968219.2971378

Reinbold, A., Seppänen, O., Peltokorpi, A., Singh, V. and Dror, E. 2019. "Integrating Indoor Positioning Systems and BIM to Improve Situational Awareness." In: Proc. 27th Annual Conference of the International Group for Lean Construction (IGLC). Dublin, Ireland, 3-5 Jul 2019: pp. 1141-1150.

Ripley, D. R. and Politzer, T. 2010. "Vision disturbance after TBI." NeuroRehabilitation, 27 (Vision Disturbance after Traumatic Brain Injury), pp. 215-216. DOI: 10.3233/NRE-2010-0599

Sawhney, A. Bashford, H. Walsh, K. and Mulky, A.R. 2003. "Agent Based Modeling and Simulations in Construction.” Winter Simulation Conference 2003, Volume 2. 
Seppänen, O. 2009. "Empirical research on the success of production control in building construction projects.” PhD Diss. Helsinki University of Technology, Finland, 187 (available at: https://aaltodoc.aalto.fi/handle/123456789/4668).

Shingo, S. 1989. A Study of the Toyota Production System from an Industrial Engineering Viewpoint. Productivity Press, Portland.

Spatz, D.M. 1999. "Leadership in the Construction Industry." Practice Periodical on Structural Design and Construction, 4: pp. 64-68.

Spatz, D.M. 2000. "Team-Building in Construction Industry." Practice Periodical on Structural Design and Construction, 5(3): pp. 93-105.

Sugimori, Y.K., Kusunoki, K., Cho, F. and Uchikawa, S. 1977. "Toyota Production System and Kanban System: Materialization of Just-in-Time and Respect-for-Human System", International Journal of Production Research, 15(6): pp. 553-564.

Tezel, A., Koskela, L. and Tzortzopoulos, P. 2009. "The Functions of Visual Management.” International Research Symposium, Salford, UK.

Tezel, A., Koskela, L.J. and Tzortzopoulos, P. 2013. "Visual Management in Industrial Construction a Case Study." In: Formoso, C.T. and Tzortzopoulos, P., Proc. 21st Annual Conference of the International Group for Lean Construction. Fortaleza, Brazil, 31-2 Aug 2013: pp 471-480.

Tezel, A., Koskela, L., Tzortzopoulos, P., Koskenvesa, A. and Sahlstedt, S. 2011. "An Examination of Visual Management on Finnish Construction Sites.” In: Rooke, J. and Dave, B., Proc. 19th Annual Conference of the International Group for Lean Construction. Lima, Peru, 13-15 Jul 2011.

Tezel, A., Tezel, T., Koskela, L. and Koskela, K. 2016. "Benefits of Visual Management in the Transportation Sector." In: Proc. 24th Annual Conference of the International Group for Lean Construction. Boston, USA, 20-22 Jul 2016.

Thomas, A., and Priyanka, J. 2014. "Study of Decentralization in Construction Companies (Kerala)" In: Proc. of the International Conference on Emerging Trends in Engineering and Management (ICETEM14) 30-31 Dec 2014, Ernakulam, India.

Valente C.P., Brandalise F.M.P. and Formoso, C.T. 2019. "Model for Devising Visual Management Systems on Construction Sites", Journal of Construction Engineer Management, 2. DOI: 10.1061/(ASCE)CO.1943-7862.0001596

Wellins, R.S., Wilson, R., Katz, A.J., Laughlin, P., Day, Jr., C.R., and Price, D. 1990. Self-directed teams: A study of current practice. Pittsburgh, PA: DDI.

Zhao, J., Seppänen, O., Peltokorpi, A., Badihi, B. and Olivieri, H. 2019. "Real-time resource tracking for analyzing value-adding time in construction." Automation in Construction, 104: pp. 52-65. https://doi.org/10.1016/j.autcon.2019.04.003 
The Role of Digitalized Visual Management to Empower Self-Managed Crews in Construction Projects

This page was intentionally left blank. 